\title{
Interpersonal Effects of Parents and Adolescents on Each Other's Health Behaviours: A Dyadic Extension of the Theory of Planned Behaviour.
}

Keven Joyal-Desmarais ${ }^{\mathrm{a} *}$, Richie L. Lenne ${ }^{\mathrm{a}}$, Mary E. Panos ${ }^{\mathrm{a}}$, Chloe O. Huelsnitz ${ }^{\mathrm{a}}$, Rachael E. Jones ${ }^{\mathrm{a}}$, Lisa A. Auster-Gussman ${ }^{\mathrm{a}}$, William F. Johnson ${ }^{\mathrm{b}}$, Jeffry A. Simpson $^{\mathrm{a}}$, and Alexander J. Rothman ${ }^{\mathrm{a}}$

${ }^{a}$ Department of Psychology, University of Minnesota, Minneapolis, Minnesota, United States ${ }^{b}$ Department of Psychology, Widener University, Chester, Pennsylvania, United States

*Correspondence concerning this article should be addressed to Keven Joyal-Desmarais (joyal008@umn.edu), Department of Psychology, University of Minnesota, 75 E River Road, Minneapolis, MN 55455.

Author Note: The first two authors contributed equally to the preparation of this manuscript. All authors contributed to the development of research questions and interpretation of findings. KJD and RLL organized and prepared these data for analysis with assistance from REJ, COH, MEP, LAAG, and WFJ. RLL and KJD conducted the analysis. KJD and RLL wrote the initial version of the manuscript with support from AJR and JAS; REJ, COH, MEP, LAAG, and WFJ provided substantive feedback on the manuscript. All authors read and approved the final manuscript. 


\section{Interpersonal Effects of Parents and Adolescents on Each Other's Health Behaviours: A Dyadic Extension of the Theory of Planned Behaviour.}

Objective: Interpersonal relationships are important predictors of health outcomes, and interpersonal influences on behaviours may be key mechanisms underlying such effects. Most health behaviour theories focus on intrapersonal factors and may not adequately account for interpersonal influences. We evaluate a dyadic extension of the Theory of Planned Behaviour by examining whether parent and adolescent characteristics (attitudes, subjective norms, perceived behavioural control, intentions) are associated with not only their own, but also each other's intentions/behaviours. Design: Using the Actor-Partner Interdependence Model, we analyse responses from 1,717 parent-adolescent dyads from the Family Life, Activity, Sun, Health, and Eating study. Main Outcome Measures: Adolescents/parents completed self-reports of their fruit and vegetable consumption, junk food and sugary drinks consumption, engagement in physical activity, and engagement in screen time sedentary behaviours. Results: Parent/adolescent characteristics are associated with each other's health-relevant intentions/behaviours above the effects of individuals' own characteristics on their own behaviours. Parent/adolescent characteristics covary with each other's outcomes with similar strength, but parent characteristics more strongly relate to adolescent intentions, whereas adolescent characteristics more strongly relate to parent behaviours. Conclusions: Parents and adolescents may bidirectionally influence each other's health intentions/behaviours. This highlights the importance of dyadic models of health behaviour and suggests intervention targets.

Keywords: Theory of Planned Behaviour, interpersonal influence, parent-adolescent relationships, health behaviour, dyadic models, FLASHE

People's close relationships are strong predictors of early mortality risk (Holt-Lunstad, Smith, \& Layton, 2010), which has been attributed to the physiological consequences of social interactions (Hostinar, Sullivan, \& Gunnar, 2014; Uchino, 2006). Yet close relationship partners also tend to engage in similar health practices (Meyler, Stimpson, \& Peek, 2007; Pachucki, Jacques, \& Christakis, 2011), likely because close others play an important role in changing and maintaining each other's behaviours (Jackson, Steptoe, \& Wardle, 2015; Lewis \& Butterfield, 2007; Martire \& Helgeson, 2017). Research has recently begun to examine the specific psychological factors that underlie interpersonal effects on health behaviours (e.g., Howland et 
al., 2016; Guidetti, Cavazza, \& Conner, 2016). The current study advances these efforts by evaluating a dyadic extension of the Theory of Planned Behaviour whereby the psychological characteristics (e.g., attitudes, subjective norms, perceived behavioural control) of parents and their adolescent children predict not only their own health intentions and behaviours, but also each other's intentions and behaviours (see Figure 1). We further evaluate such effects across four behavioural domains (fruit and vegetable consumption; junk food and sugary drinks consumption; engagement in physical activity; engagement in screen time sedentary behaviours).

\section{How Well do Health Behaviour Theories Account for Interpersonal Influence?}

Most psychological theories of health behaviour focus on intrapersonal explanations, such as how individuals' own characteristics relate to their own behaviours (Ajzen, 1991; Prochaska, Norcross, \& DiClemente, 2013; Sheeran, Klein, \& Rothman, 2017). For example, the Theory of Planned Behaviour (TPB; Ajzen, 1991; Armitage \& Conner, 2001) maintains that people's attitudes (e.g., 'I think exercise is good'), subjective norms (e.g., 'I think others believe exercise is good'), and perceived behavioural control (PBC; e.g., 'I'm confident in my ability to exercise') predict their intentions (e.g., 'I will exercise'), which in turn predict their behaviours (e.g., exercising). Interpersonal explanations, which delineate how other people's characteristics affect a person's behaviour, have received less attention. The TPB and similar theories acknowledge the influence of other people on individuals' behaviours, but this effect is operationalized through intrapersonal channels (e.g., how alcohol consumption by adolescents' peers influence their own drinking by changing their subjective norms regarding alcohol).

Such accounts of interpersonal influence are insufficient for several reasons. First, if interpersonal factors (e.g., a friend's attitudes) exert influence through intrapersonal factors (e.g., one's own subjective norms), assessing only intrapersonal factors does not allow inferences 
regarding which interpersonal factors matter nor how strongly each operate. Second, when only intrapersonal factors are assessed, one cannot rule out that interpersonal factors also contribute to a person's decisions and behaviour independent of the intrapersonal factors examined. This is important as studies using a dyadic approach to model health behaviours (i.e., assess the same beliefs and behaviours in both relational partners) find that the beliefs of relationship partners often predict each person's behaviour, even when accounting for people's own characteristics. For example, in a study of cancer screening, wives' and husbands' attitudes predicted both their own and each other's screening intentions (Manne, Kashy, Weinberg, Boscarino, \& Bowen, 2012). Similarly, in parent-adolescent dyads, each person's autonomous motivation to consume fruits/vegetables also predicted their own and each other's eating behaviour (Dwyer et al., 2017). These findings reinforce calls to test dyadic health behaviour models that specify both intrapersonal and interpersonal factors (Howland et al., 2016; Karney et al., 2010).

\section{Developing a Dyadic Extension of the Theory of Planned Behaviour}

One way to develop dyadic models of health behaviour is to extend current theories by adding interpersonal effects that mirror intrapersonal effects. For example, the TPB posits that a person's attitudes, subjective norms, and PBC predict their intentions. A dyadic extension can incorporate the effects of a close other's attitudes, subjective norms, and PBC on her or his own intentions (intrapersonal effects), along with the effects of the close other's own attitudes, subjective norms, and PBC on her or his partner's intentions (interpersonal effects; Karney et al., 2010). Dyadic models also account for within-dyad similarity by modelling the correlation between partners' characteristics and outcomes (e.g., between their attitudes; Kenny, Kashy, \& Cook, 2006). Howland and colleagues (2016), for example, evaluated whether romantic partners' beliefs (attitudes, subjective norms, PBC) were associated with each other's physical activity 
intentions and found interpersonal effects for each person's PBC. Their model, however, was only a partial extension of the TPB because they did not examine associations with behaviour.

The current study tests a more complete dyadic extension of the TPB by examining whether and how both relationship partners' attitudes, subjective norms, $\mathrm{PBC}$, and intentions are associated with each other's health intentions and behaviours. We analyse data from a U.S. national survey of 1,717 parent-adolescent dyads (Nebeling et al., 2017) that assessed health beliefs and behaviours for both dyad members across four domains: fruit and vegetable consumption (FV), junk food and sugary drinks consumption (JF), engagement in physical activity (PA), and engagement in screen time sedentary behaviours (SB). To date, dyadic studies of health behaviour have focused on romantic relationships (e.g., Howland et al., 2016; Manne et al., 2012) but there is growing interest in parent-adolescent relationships (e.g., Guidetti et al., 2014, 2016), the dynamics of which differ substantially from romantic relationships. For instance, parents can use their power to obtain acquiescence from their adolescents (Henry, Wilson, \& Peterson, 1989) in ways that romantic partners cannot. Because adolescence is a time in which children seek greater autonomy and relative power (Koepke \& Denissen, 2012), adolescents may also exert influence on their parents (e.g., by playing an active role in grocery shopping). Dyadic models can provide insights into these dynamics by explicitly modelling the interpersonal effects of parents on adolescents and of adolescents on parents.

We examine two alternative conceptualizations of a dyadic extension of the constructs identified by the TPB (see Figure 1). Model I is grounded on the assumption that all influences on people's behaviour (intrapersonal and interpersonal) occur indirectly through intentions. Model II allows these effects to occur either through intentions or directly on behaviour. According to the TPB, PBC can directly affect people's own behaviour, but it is unclear whether 
PBC and only PBC has a direct effect on another person's behaviour. Because we cannot rule out any interpersonal pathway a priori, Models I and II offer contrasts to determine whether any given belief has indirect and/or direct interpersonal associations with behaviours.

We had several a priori expectations. First, consistent with intrapersonal tests of the TPB, we expected individuals with stronger attitudes, subjective norms, and PBC regarding a given behaviour (FV, JF, PA, or SB) to have stronger intentions to engage in that behaviour. Such intentions were expected to be associated with higher rates of that behaviour (Figure 1, grey paths). Second, we expected interpersonal effects (Figure 1, black paths) would emerge, above and beyond the intrapersonal effects in each model. We expected parents' (adolescents') attitudes, subjective norms, and PBC for each behaviour to be associated with their adolescents' (parents') intentions, and parents' (adolescents') intentions to be associated with their adolescents' (parents') behaviour. We did not expect all interpersonal paths to be significant but did anticipate interpersonal effects would emerge for each behavioural domain.

\section{Method}

The FLASHE parent sample was recruited by the Ipsos Consumer Opinion Panel in all regions of the U.S. in 2014 (Nebeling et al., 2017; Oh et al., 2017). Eligible parents (aged 18 years or older) lived with at least one adolescent (aged 12-17 years). For each household, one adolescent was randomly selected to participate with their parent. 5,027 dyads were invited to participate and 1,945 enrolled. Participants responded to two surveys that assessed diet (e.g., FV and JF beliefs and behaviours) and physical activity (e.g., PA and SB beliefs and behaviours). We analysed the data from all dyads that completed the diet $(\mathrm{N}=1646)$ and/or the physical activity $(\mathrm{N}=1644)$ surveys $-1,717$ dyads in all. Our adolescent sample was $50 \%$ female and $50 \%$ male adolescents, whereas parents were predominantly female (74\%). Respondents 
predominantly identified as non-Hispanic White (70\% of parents; $64 \%$ of adolescents), followed by non-Hispanic Black (17\% of either parents/adolescents), and Hispanic (7\% parents; $10 \%$ adolescents). Additional demographic information is available in Table S1 in the supplemental materials, and further details on FLASHE's methods/recruitment are available elsewhere (Mâsse \& Lytle, 2017; Nebeling et al., 2017; Oh et al., 2017). Data were downloaded April 4, 2017 and can be obtained at: https://cancercontrol.cancer.gov/brp/hbrb/flashe.html.

\section{Preregistration}

Our study protocol was preregistered prior to accessing FLASHE data (osf.io/zvzke) and our analysis code is available online (osf.io/x3jav). We followed our preregistration, with two exceptions. First, we did not preregister an intentions measure, but added it later to better capture the TPB. Analyses excluding intentions are consistent with the results here. Second, we did not preregister analyses for the SB domain, but applied the protocol specified for the other domains. We also preregistered moderation analyses, but report them elsewhere (Lenne et al., in press).

\section{Measures}

\section{Beliefs and intentions.}

Although FLASHE was not designed to assess TPB variables formally, it contained items that can be used to operationalize the four key constructs identified by the TPB. Attitudes, subjective norms, $\mathrm{PBC}$, and intentions were assessed separately for adolescents and parents for each behavioural domain using 5-point Likert-type response formats $(1=$ 'strongly disagree'; $5=$ 'strongly agree'). Items assessing beliefs/intentions for FV and PA focused on engaging in these behaviours, whereas JF and SB items generally focused on limiting the behaviours. To facilitate comparisons across the four domains, items on limiting behaviours were reverse-scored, such that higher scores indicated more positive beliefs/intentions toward engaging in the behaviour. 
When multiple items assessed a construct, the mean was used. The unstandardized means and standard deviations are available in Table $\mathrm{S} 2$ in the supplemental materials.

Attitudes toward each behaviour were assessed with a single item, 'I would [engage in behaviour] because it's an important thing for me to do' (e.g., 'I would eat fruits and vegetables every day because it's an important thing for me to do'). Two additional items were used to assess attitudes toward PA ('If I were to be physically active most days of the week, it would be fun,' and 'I don't like to exercise' [reverse-coded]; standardised coefficient alphas $\left[\alpha_{s}\right]$ were .67 for parents, and .65 for adolescents). Two items measured subjective norms for adolescents. The first assessed adolescents' perception of their peers' behaviours (i.e., a descriptive norm; 'My friends [engage in behaviour] most days of the week'); the second assessed their perception of how peers would react if they engaged in a certain behaviour (i.e., an injunctive norm; 'I would [engage in behaviour] because others would be upset with me if I didn't'). The two items were discrepant $\left(\alpha_{s}=.10,-.08, .27\right.$, and -.18 for FV, JF, PA, and SB respectively); this is typical as injunctive and descriptive norms are independent aspects of subjective norms (Rivis \& Sheeran, 2003). Parents completed only the item assessing the injunctive norm. $P B C$ was assessed using one item asking about parents' and adolescents' confidence in their ability to enact each health behaviour ('I feel confident in my ability to [engage in behaviour]'). Finally, parent and adolescent intentions to enact each behaviour were assessed with one item: 'I would [engage in behaviour] because I have thought about it and decided that I want to [engage in behaviour]'

\section{Behavioural assessments.}

Items assessing FV, JF, PA, and SB were selected following NCI's recommendations and standard practice, ensuring that parents/adolescents completed age-appropriate measures. Each construct was coded such that higher scores indicated more engagement in each behaviour. 
Fruit/vegetable and junk food/sugary drinks consumption (FV/JF). To assess FV/JF, FLASHE employed items from the Dietary Screener Questionnaire used in the 2009-2010 National Health and Nutrition Examination Survey (NHANES; Epidemiology and Genomics Research Program, National Cancer Institute, 2017) and the National Youth Physical Activity and Nutrition Survey (CDC, 2017). Items were modified to be age-appropriate. Six-point scales assessed the frequency with which participants consumed various foods over the prior seven days $(1=$ not having consumed the food; $6=3$ or more times per day). Following Dwyer et al. (2017), six items assessed FV consumption (e.g., apple, bananas, green salad) and 16 items assessed JF consumption (e.g., candy or chocolate, ice cream or other frozen desserts, potato chips, corn chips, cheese puffs). Adolescents and parents completed the same items, and mean scores were calculated for each variable $(\mathrm{FV}, \mathrm{JF})$. The NHANES dietary screener was validated against a 24-hour recall of diet in several studies (e.g., Thompson, Midthune, Kahle, \& Dodd, 2017). Additional information about FLASHE's dietary screener is available (Smith et al., 2017). Physical activity/Screen time sedentary behaviour (PA/SB). Adolescent PA was assessed using the Youth Activity Profile (YAP; Saint-Maurice et al., 2017; Saint-Maurice \& Welk, 2015). We used eight items from the YAP, excluding items assessing activities that took place in school. Example items asked adolescents to 'summarize [their] level of activity last week' (1= 'I did not do any physical activity in my free time'; 5 = 'I very often [7 or more times] did physical activity in my free time') or to indicate the number of days during the week they walked/biked to or from school ( $0=$ ' 0 days [never]'; $4=$ '4-5 days [most every day]'). Items were scaled from zero to one, and a mean was calculated. Parent PA was assessed with the International Physical Activity Questionnaire (IPAQ) Short Form (Craig et al., 2003), which asked them to indicate the number of days during the prior week they engaged in at least 10 minutes of walking, moderate 
activity, or vigorous activity, and the usual amount of time spent in those activities each day. The IPAQ was scored in units of metabolic equivalent task (MET) minutes following recommended protocol (The IPAQ Group, 2017). The YAP and IPAQ have been validated against accelerometer data (Craig et al., 2003; Saint-Maurice et al., 2017; Saint-Maurice \& Welk, 2015).

For adolescent SB, we used the mean of four items from the YAP (Saint-Maurice et al., 2017; Saint-Maurice \& Welk, 2015) that assessed average free time per day spent using the computer or a cell phone, watching TV, and playing videogames during the preceding 7 days $(1=$ 'I didn't really use [device] at all'; 5 = 'I used [device] more than 3 hours'). For parent SB, we used six items from the Project Eat Surveys (Taverno Ross, Larson, Graham, \& NeumarkSztainer, 2014), the Growing Up Today Study (Falbe et al., 2013), and the TREC Idea Study (Lytle, 2009), some of which were modified for FLASHE. Items were similar to the adolescent items and assessed time per day spent using the computer or a cell phone, watching TV, playing handheld/console videogames, or using electronic readers ( $1=$ not at all; $6=6+$ hours $)$. We calculated mean scores for each parent but truncated 20 outliers such that scores reflect engaging in SB for no more than 18 hours a day; this decision did not affect our conclusions.

\section{Statistical Analyses}

We conducted analyses using the Actor-Partner Interdependence Model (APIM; Kenny et al., 2006). The APIM uses nested structures to test the independent contribution of actor effects (i.e., intrapersonal effects, such as adolescent attitudes on adolescent behaviour) and partner effects (i.e., interpersonal effects, such as parent attitudes on adolescent behaviour). Following APIM procedures, we examined Models I and II using structural equation modelling with the lavaan package (Rosseel, 2012) in R (R Core Team, 2017). Models were specified according to the path diagrams in Figure 1, using full information maximum likelihood estimation to handle 
missing data. Prior to analyses, we applied log-transformations on skewed variables (adolescent JF behaviour; parent JF and PA behaviours) and standardized variables to ease comparisons.

\section{Results}

We present the actor effects followed by summaries of the partner effects. We compare the average partner effects for (1) adolescent-to-parent versus parent-to-adolescent and (2) intention versus behaviour outcomes. Bivariate correlations are presented in Tables S3 to S6 of the supplemental files. Table 1 presents the fit indices for Models I and II for each behavioural domain. Model I explained a medium-to-large proportion of the variance in parent and adolescent behavioural intentions (33.3\% to $52.5 \%)$ but explained less variance in parent and adolescent behaviour ( $0.3 \%$ to $16.4 \%)$. Model II consistently accounted for more variance in behaviour (2.9\% to $31.2 \%$ ) than Model I and almost always yielded better fit indices.

\section{Actor Effects Within a Dyadic Extension of the TPB}

Table 2 presents the actor effects for Models I and II for each behavioural domain. According to the TPB, people's attitudes, subjective norms, and PBC should be positively associated with their intentions, and their intentions should be positively associated with their behaviour. Among the 32 actor effects representing these pathways in Model I, 31 were significant and positive. Of the same 32 effects in Model II, 28 were significant and positive. Model II also allowed us to test direct effects of PBC on each of the four health behaviours. These effects were significant and positive for three of the four behaviours. This pattern of results is consistent with traditional TPB hypotheses and reveals that these effects generally remain significant even when controlling for the TPB beliefs/intentions of close others.

Model II also examined whether attitudes and subjective norms were directly associated with behaviour over the association between intentions and behaviour. Attitudes typically were 
positively associated with behaviour for parents (3 significant paths of 4), but not for adolescents (1 significant path of 4). Subjective norms were related to behaviour for both parents and adolescents (7 significant paths of 8). Unexpectedly, parents' subjective norms were negatively associated with their JF and SB behaviours, whereas all adolescent actor effects were positive.

\section{Partner Effects Within a Dyadic Extension of the TPB}

Table 3 presents all estimated partner effects for Models I and II for each behavioural domain. Significant partner effects emerged for every model (see columns of Table 4); thirteen significant partner effects were found for Model I, and 21 were found for Model II. Table 4 presents the average absolute (i.e., non-directional) magnitude of all partner effects, broken down by type of partner effect (i.e., regressing adolescent outcomes on parent variables versus parent outcomes on adolescent variables) and type of outcome (i.e., partner effects on intentions versus behaviours). Using the information in Tables 3 and 4, we describe the frequency with which partner effects were significant and the average magnitude of each effect type. Across the four behavioural domains, there were slightly fewer adolescent-to-parent than parent-to-adolescent partner effects (Model I: 5 vs. 8 significant effects; Model II: 10 vs. 11 significant effects). However, the average magnitude of partner effects was similar between adolescent-to-parent and parent-to-adolescent effects (see Table 4). The results from Models I and II are equivalent when accounting for intentions. Overall, adolescent-to-parent partner effects were less frequently significant than parent-to-adolescent partner effects (3 vs 6 significant effects) and were smaller in average magnitude (.023 versus .039). When accounting for behaviours, adolescent-to-parent partner effects were slightly more frequently significant than parent-to-adolescent partner effects in Model II (7 vs. 5 significant effects), but not Model I (2 vs. 2 significant effects). However, in both Models, the average magnitude of adolescent-to-parent partner effects was greater than that 
of parent-to-adolescent partner effects (Model I: .088 vs. .060; Model II: .063 vs. .039).

\section{Discussion}

\section{Evidence of intrapersonal effects delineated by the TPB}

The intrapersonal paths specified by the traditional TPB-both in Models I and II-were statistically significant in the theorized direction, with only a few exceptions. This is noteworthy because these intrapersonal effects controlled for their interpersonal counterparts, resulting in greater precision. Estimating only intrapersonal effects when partners are non-independent (e.g., when their attitudes are correlated) can lead to overestimation, and similar biasing can arise when interpersonal effects are estimated without controlling for intrapersonal effects. Dyadic models improve inferences by modelling both types of effects explicitly (Kenny et al., 2006).

\section{Evidence of Interpersonal Effects in the Dyadic Extension of the TPB}

We found statistically significant partner effects for Models I and II in each behavioural domain (FV, JF, PA, SB) and on both intentions and behaviours. Partner effects made significant contributions above actor effects in both models. This suggests it is unlikely that partners exert their influence solely through changes in actors' own beliefs, as such effects were accounted for by modelling correlations among each corresponding TPB variable between parents and adolescents. Since intrapersonally-oriented TPB intervention strategies can elicit change in behaviours (Sheeran et al., 2016), there is value in determining whether eliciting change in partners' beliefs is also effective. Findings from future longitudinal and experimental research will also determine whether the partner effects observed in this correlational study are causal.

\section{Bidirectional influence}

Overall, the direct partner effects from adolescent-to-parent and from parent-toadolescent were comparable in frequency and magnitude, suggesting that interpersonal 
influences may often be bidirectional. Other studies also find bidirectional partner effects between children and parents (Coesens, Mol, Bourdeaudhuij, \& Buysse, 2010; Dwyer et al., 2017). However, research on similarity in parent-child behaviour typically emphasizes parental influence on their children's behaviours (Guidetti et al., 2012; Golan \& Crow, 2004; Lewis \& Butterfield, 2007) without considering the influence of children on their parents. Given that children can influence their parents' decisions (e.g., affecting purchases; Wilson \& Wood, 2004), future interventions might examine the effects of strategies that target both influence channels. For example, do nutrition campaigns that target adolescent characteristics also elicit changes in parental eating behaviour? Could interventions leverage adolescent-to-parent and parent-toadolescent influence channels synergistically to promote behaviour maintenance? Further developments in dyadic theories of health behaviour could inform such efforts.

\section{Intentions Versus Behaviours}

On average, parent characteristics were more strongly associated with adolescent intentions than were adolescent characteristics with parent intentions. However, adolescent characteristics were more strongly associated with parent behaviours than were parent characteristics with adolescent behaviours. Additionally, parent characteristics were similarly associated with adolescent intentions and behaviours, but adolescent characteristics were more strongly associated with parent behaviours than intentions. What might account for these patterns? Some of these differences may arise from qualities unique to the social roles played by parents and children. For example, parents tend to have more power than adolescents, and power affects the ways in which individuals influence one another (Simpson, Farell, Oriña, \& Rothman, 2015). Parents typically have greater authority and credibility, which helps them persuade their adolescents to change their intentions (Pornpitakpan, 2004). Adolescents may have more 
difficulty changing their parents' intentions, but may persist in requesting an outcome (e.g., eating pizza) until their parents give in (e.g., McDermott, O’Sullivan, Stead, \& Hastings, 2006). Such concessions do not require parents to change their general intentions toward a behaviour. For example, parents may intend to avoid a behaviour (e.g., JF/SB), but find themselves occasionally capitulating, creating discrepancies between their intentions and behaviours.

Another difference in social roles is that parents are expected to support their children more than the reverse. Parents may accommodate their children by changing their behaviours (e.g., bike or play video games with their children to support a new interest), without requiring a change in their intentions to enact the behaviour for its own sake. Children, however, may be less likely to alter their behaviours simply for their parents' sake. Future research should delineate whether, when, and why parents and children exert differential influence on each other's healthrelevant intentions and behaviours. When addressing such questions, a developmental approach may prove insightful. For example, parents may exert greater influence on younger children's eating behaviours (e.g., by controlling their home food environment; Larsen et al., 2015) than on adolescents' eating behaviours, especially as they spend more time outside the home. In contrast, children's influence on their parents may increase over time as they learn how to better influence their parents through practice, and gain greater credibility and relative power as they age.

\section{Comparing Findings Across Attitudes, Subjective Norms, and PBC}

Of the three TPB belief variables, subjective norms had the largest number of partner effects on both intentions and behaviours. Attitudes had several significant associations with partner intentions, but they were not directly associated with partner behaviours, whereas PBC had several significant associations with partner behaviours, but fewer with partner intentions. These patterns differ from Howland et al. (2016), who found that PBC, but not attitudes or 
subjective norms, were associated with partner intentions. This may reflect differences between parent-adolescent and romantic relationships. However, there are too few dyadic health studies and models to interpret these differences meaningfully, and the possibility remains that these differences reflect methodological rather than psychosocial factors. Future research needs to establish which constructs are most likely to generate partner effects, how strong each effect is, and whether or how their operations vary across different types of relationships.

Additionally, the present study focused on the impact of interpersonal factors on parent and adolescent behaviours. Future research should examine dyadic or "relationship-level" factors - characteristics that describe the dyad itself rather than either partner. These might include assessments of the overall quality of the relationship or engagement in joint planning activities (i.e., dyadic planning; Burkert, Scholz, Gralla, Roigas, \& Knoll, 2011). Dyadic factors could be incorporated into future models as predictors or mediators of interpersonal effects (e.g., how dyadic planning predicts physical activity), or as moderators of interpersonal effects (e.g., relationship quality may moderate the magnitude of interpersonal effects; Howland et al., 2016).

\section{Comparing Findings Across Model I and Model II}

Model II offers a more complete but less parsimonious evaluation of interpersonal effects than Model I. Given that Model II fit indices outperformed Model I and many significant partner effects were observed between beliefs and behaviours, future studies should continue to examine the full set of pathways specified in Model II. Because some interpersonal paths may contribute less than others (e.g., we found no significant direct partner effect from attitudes to behaviour), future work should establish the reliability and usefulness of each pathway in Model II.

\section{Comparing Findings Across Behavioural Domains}

The degree to which TPB constructs account for intentions/behaviours varies across 
different behaviours (McEachan et al., 2016). We extend research documenting variation in intrapersonal effects by examining how interpersonal effects also vary across behaviours.

Healthy vs. unhealthy behaviours. Intentions more strongly covaried with healthy (FV and PA) than unhealthy (JF and SB) behaviours with respect to both intrapersonal and interpersonal effects. This may be because unhealthy behaviours, relative to healthy ones, are more responsive to contextual/impulsive factors (e.g., craving junk food and impulsively buying some) than to deliberate plans (e.g., a person may be less likely to plan to be sedentary; Hofmann, Friese, \& Wiers, 2008). This distinction is reflected in how constructs were measured in the FLASHE survey. FV and PA items were framed around active engagement in a behaviour, whereas JF and SB items were framed in terms of limiting one's engagement in a behaviour. Given that cognitions about limiting a behaviour are distinct from those about doing a behaviour (Richetin, Conner \& Perugini, 2011), future work should address this distinction.

Another difference between healthy and unhealthy behaviours was that parent (but not adolescent) subjective norms were negatively related to parent/adolescent behaviour for JF/SB. This was unexpected and all other significant associations with parent/adolescent subjective norms were positive. This may reflect the differential operation of doing vs. limiting a behaviour (Richetin et al., 2011), but also of injunctive vs. descriptive norms (Rivis \& Sheeran, 2003), as our measure of subjective norms differed between parents/adolescents. Unfortunately, we cannot tease apart these explanations without a measure of parent descriptive norms. Future work should examine the reliability of these effects to ascertain that they are not methodological artefacts.

Eating vs. physical activity behaviours. Adopting a dyadic, relational focus may reveal other meaningful distinctions between behavioural domains. There are certain behaviours that parents and adolescents may be more likely to engage in while in one another's presence. For 
example, eating behaviours may be more coordinated than physical activity behaviours and, if so, one might expect stronger patterns of interpersonal influence on eating behaviours. We found evidence consistent with this pattern, but differences in effect size were smaller than between promoting healthy versus limiting unhealthy behaviours. Research has examined how parents influence their children/adolescents' physical activity (Beets, Cardinal, \& Alderman, 2010) and eating behaviours (Wang, Beydoun, Li, Liu, \& Moreno, 2011), but studies generally do not compare influences across domains (with some exceptions; e.g., Berge, Wall, Loth, \& NeumarkSztainer, 2010). Fewer studies, if any, take a dyadic perspective to consider how children/adolescents may influence their parents differentially across behavioural domains.

\section{A Critical Need for Longitudinal Dyadic Research}

Although the FLASHE data are dyadic, they are also cross-sectional. Thus, the direction of our estimated effects cannot be ascertained. For instance, differences in behaviour may account for differences in intention (e.g., via social modelling), rather than the reverse (see Weinstein, 2007, on limitations of cross-sectional tests of health behaviour theories). Further, belief and intention items were framed in terms of future behaviour, or behaviour in general (i.e., without a time-frame), but participants reported recent patterns of behaviour. Though modelling behaviour as an outcome is common when working with cross-sectional data, doing so assumes that concurrently measured predictors are reflective of their status preceding the behaviour. If this assumption is false, it may make sense to model behaviour as a predictor of intention. Following a reviewer's suggestion, we tested an Alternative Model in which behaviour and the three TPB beliefs predict intention (see Figure S1 and Tables S7-S9 of the supplemental files). The results were congruent with those from Models I and II and supported the premise that interpersonal associations can be observed over and above intrapersonal ones. However, it 
remains that no inferences can be made regarding the temporal ordering of these effects. It is critical that future research efforts prioritize the collection of longitudinal dyadic data sets.

\section{Limitations and Strengths}

The current study has several limitations and strengths. Although the interpersonal result were robust across the four behavioural domains, they should be viewed as preliminary evidence of partner effects. First, as discussed above, the FLASHE data are cross-sectional. Second, some TPB constructs were assessed with one or two items, limiting their reliability. Third, FLASHE was not formally designed to test the TPB, meaning that some items were operationalized slightly differently from traditional assessments used in TPB research. For example, intention items were framed in terms of wanting/deciding rather than intending, and an attitude item asked about the importance of the behaviour for oneself, possibly creating overlap with self-identity factors (e.g., Spark \& Guthrie, 1998). These deviations preclude us from drawing strong conclusions regarding each specific TPB predictor and underscore the value of replicating our findings with better assessments. That said, constructs used across health behaviour theories often overlap (Sheeran et al., 2017), and the items we used replicated prior intrapersonal TPB findings (Armitage \& Conner, 2001; McEachan et al., 2016). Although we are limited in our ability to draw inferences about a given predictor, our observation of interpersonal effects across predictors supports our claim that dyadic extensions to social-cognitive theories hold value.

Fourth, our behavioural measures consisted of self-reports and, therefore, relied on participants' ability to recall their behaviours. The IPAQ, YAP, and NHANES dietary screener have each been validated against external measures (Craig et al., 2003; Saint-Maurice et al., 2017; Thompson et al., 2017), but direct measures of behaviour remain the gold standard. Selfreports are prone to response biases, but they may affect estimates of intrapersonal effects more 
than interpersonal effects, given that the latter involve responses from two individuals.

There are also strengths. FLASHE was designed to evaluate dyadic models via the inclusion of many identical measures answered by both parents and their adolescents. Our analyses also involved 1,717 dyads (3,434 individuals), whereas many dyadic studies have much smaller sample sizes. FLASHE was designed to maximize sample similarity to many U.S. demographic variables (Nebeling et al., 2017; Oh et al., 2017). The effects, however, may not generalize to different types of relationships (e.g., romantic partners, friends) or to different regional/cultural contexts. Finally, the concurrent assessments of FV, JF, PA, and SB allowed us to replicate findings across four distinct domains, increasing confidence in our results.

\section{Conclusion}

In this research, we evaluated a dyadic extension of the Theory of Planned Behaviour that modelled patterns of associations between parents and adolescents across four health behaviours. We obtained consistent evidence of interpersonal effects; each individual's characteristics were significantly associated with the other person's health-relevant intentions/behaviours, accounting for the effect of each individual's characteristics on their own intentions/behaviours. We observed stronger effects from parents-to-adolescents on adolescent intentions, and stronger effects from adolescents-to-parents on parent behaviours. These results underscore the importance of measuring and modelling dyadic influence on health behaviours.

\section{Acknowledgements}

This research was supported by a Social Sciences and Humanities Research Council (SSHRC) of Canada doctoral fellowship to the first author.

\section{Declaration of interest}

The authors declare that they have no conflict of interest. 


\section{References}

Ajzen, I. (1991). The theory of planned behavior. Organizational Behavior and Human Decision Processes, 50, 179-211.

Armitage, C. J., \& Conner, M. (2001). Efficacy of the theory of planned behaviour: A metaanalytic review. British Journal of Social Psychology, 40(4), 471-499.

Beets, M. W., Cardinal, B. J., \& Alderman, B. L. (2010). Parental social support and the physical activity-related behaviors of youth: A review. Health Education \& Behavior, 37(5), 621644.

Berge, J. M., Wall, M., Loth, K., \& Neumark-Sztainer, D. (2010). Parenting style as a predictor of adolescent weight and weight-related behaviors. Journal of Adolescent Health, 46(4), 331-338.

Bergkvist, L., \& Rossiter, J. R. (2007). The predictive validity of multiple-item versus single-item measures of the same constructs. Journal of Marketing Research, 44(2), 175-184.

Burkert, S., Scholz, U., Gralla, O., Roigas, J., \& Knoll, N. (2011). Dyadic planning of healthbehavior change after prostatectomy: A randomized-controlled planning intervention. Social Science \& Medicine, 73(5), 783-792.

Centers for Disease Control and Prevention. (2010). National Youth Physical Activity and Nutrition Survey [Questionnaire]. Retrieved from ftp://ftp.cdc.gov/pub/data/yrbs/nypans/2010nypans_questionnaire.pdf

Coesens, C., De Mol, J., De Bourdeaudhuij, I., \& Buysse, A. (2010). The role of interpersonal influence in families in understanding children's eating behavior: A social relations model analysis. Journal of Health Psychology, 15(8), 1267-1278.

Craig, C. L., Marshall, A. L., Sjöström, M., Bauman, A. E., Booth, M. L., Ainsworth, B. E., ... Oja, P. (2003). International physical activity questionnaire: 12-country reliability and 
validity. Medicine \& Science in Sports \& Exercise, 35(8), 1381-1395.

Dwyer, L. A., Bolger, N., Laurenceau, J. P., Patrick, H., Oh, A. Y., Nebeling, L. C., \& Hennessy, E. (2017). Autonomous motivation and fruit/vegetable intake in parent-adolescent dyads. American Journal of Preventive Medicine, 52(6), 863-871.

Epidemiology and Genomics Research Program, National Cancer Institute (2016). Dietary screener questionnaire in the NHANES 2009-2010: Background [Questionnaire Resource]. Retrieved from http://epi.grants.cancer.gov/nhanes/dietscreen/

Falbe, J., Rosner, B., Willett, W. C., Sonneville, K. R., Hu, F. B., \& Field, A. E. (2013). Adiposity and different types of screen time. Pediatrics, 132(6), e1497-e1505.

Golan, M., \& Crow, S. (2004). Targeting parents exclusively in the treatment of childhood obesity: Long-term results. Obesity Research, 12(2), 357-361.

Guidetti, M., Cavazza, N., \& Conner, M. (2016). Social influence processes on adolescents' food likes and consumption: The role of parental authoritativeness and individual selfmonitoring. Journal of Applied Social Psychology, 46, 114-128.

Guidetti, M., Cavazza, N., \& Graziani, A., R. (2016). Healthy at home, unhealthy outside: Food groups associated with family and friends and the potential impact on attitude and consumption. Journal of Social and Clinical Psychology, 33(4), 343-364.

Guidetti, M., Conner, M., Prestwich, A., \& Cavazza, N. (2012). The transmission of attitudes towards food: Twofold specificity of similarities with parents and friends. British Journal of Health Psychology, 17(2), 346-361.

Henry, C. S., Wilson, S. M., \& Peterson, G. W. (1989). Parental power bases and processes as predictors of adolescent conformity. Journal of Adolescent Research, 4(1), 15-32.

Hofmann, W., Friese, M., \& Wiers, R. W. (2008). Impulsive versus reflective influences on 
health behavior: A theoretical framework and empirical review. Health Psychology Review, 2(2), 111-137.

Holt-Lunstad, J., Smith, T. B., \& Layton, J. B. (2010). Social relationships and mortality risk: a meta-analytic review. PLoS medicine, 7(7), e1000316.

Hostinar, C. E., Sullivan, R. M., \& Gunnar, M. R. (2014). Psychobiological mechanisms underlying the social buffering of the hypothalamic-pituitary-adrenocortical axis: A review of animal models and human studies across development. Psychological Bulletin, 140(1), 256-282.

Howland, M., Farrell, A. K., Simpson, J. A., Rothman, A. J., Burns, R. J., Fillo, J., \& Wlaschin, J. (2016). Relational effects on physical activity: A dyadic approach to the theory of planned behavior. Health Psychology, 35(7), 733-741.

Hu, L. T., \& Bentler, P. M. (1999). Cutoff criteria for fit indexes in covariance structure analysis: Conventional criteria versus new alternatives. Structural Equation Modeling: A Multidisciplinary Journal, 6(1), 1-55.

Iacobucci, D. (2010). Structural equations modeling: Fit indices, sample size, and advanced topics. Journal of Consumer Psychology, 20(1), 90-98.

Jackson, S. E., Steptoe, A., \& Wardle, J. (2015). The influence of partner's behavior on health behavior change: The English Longitudinal Study of Ageing. JAMA Internal Medicine, $175(3), 385-392$.

Karney, B. R., Hops, H., Redding, C. A., Reis, H. T., Rothman, A. J., \& Simpson, J. A. (2010). A framework for incorporating dyads in models of HIV-prevention. AIDS and Behavior, 14(2), 189-203.

Kenny, D. A., Kashy, D. A., \& Cook, W. L. (2006). Dyadic data analysis. New York: Guilford Press. 
Koepke, S., \& Denissen, J. J. A. (2012). Dynamics of identity development and separationindividuation in parent-child relationships during adolescence and emerging adulthood: A conceptual integration. Developmental Review, 32(1), 67-88.

Larsen, J. K., Hermans, R. C., Sleddens, E. F., Engels, R. C., Fisher, J. O., \& Kremers, S. P. (2015). How parental dietary behavior and food parenting practices affect children's dietary behavior. Interacting sources of influence? Appetite, 89, 246-257.

Lenne, R. L., Joyal-Desmarais, K., Jones, R. E., Huelsnitz, C. O., Panos, M., E., ... Simpson, J.A. (in press). Parenting styles moderate how parent and adolescent beliefs shape each other's eating and physical activity: Dyadic evidence from a cross-sectional, U.S. national survey. Journal of Experimental Social Psychology. Preprint available: psyarxiv.com/2vdgf/

Lewis, M. A., \& Butterfield, R. M. (2007). Social control in marital relationships: Effect of one's partner on health behaviors. Journal of Applied Social Psychology, 37(2), 298-319.

Lytle, L. A. (2009). Examining the etiology of childhood obesity: The IDEA Study. American Journal of Community Psychology, 44(3-4), 338-349.

Manne, S., Kashy, D., Weinberg, D. S., Boscarino, J. A., \& Bowen, D. J. (2012). Using the interdependence model to understand spousal influence on colorectal cancer screening intentions: A structural equation model. Annals of Behavioral Medicine, 43(3), 320-329.

Martire, L. M., \& Helgeson, V. S. (2017). Close relationships and the management of chronic illness: Associations and interventions. American Psychologist, 72(6), 601.

Mâsse L. C., \& Lytle L. A. (2017). Advancing knowledge of parent-child dyadic relationships about multiple cancer preventive health behaviors: The National Cancer Institute Family Life, Activity, Sun, Health, and Eating (FLASHE) study. American Journal of Preventive Medicine, 52(6), 833-835. 
McDermott, L., O’Sullivan, T., Stead, M., \& Hastings, G. (2006). International food advertising, pester power and its effects. International Journal of Advertising, 25(4), 513-539.

McEachan, R., Taylor, N., Harrison, R., Lawton, R., Gardner, P., \& Conner, M. (2016). Metaanalysis of the reasoned action approach (RAA) to understanding health behaviors. Annals of Behavioral Medicine, 50(4), 592-612.

Meyler, D., Stimpson, J. P., \& Peek, M. K. (2007). Health concordance within couples: A systematic review. Social Science \& Medicine, 64(11), 2297-2310.

Nebeling, L. C., Hennessy, E., Oh, A. Y., Dwyer, L. A., Patrick, H., Blanck, H. M., ...Yaroch, A. L. (2017). The FLASHE study: Survey development, dyadic perspectives, and participant characteristics. American Journal of Preventive Medicine, 52(6), 839-848.

Oh, A. Y., Davis, T., Dwyer, L. A., Hennessy, E., Li, T., Yaroch, A. L., \& Nebeling, L. C. (2017). Recruitment, enrollment, and response of parent-adolescent dyads in the FLASHE study. American Journal of Preventive Medicine, 52(6), 849-855.

Pachucki, M. A., Jacques, P. F., \& Christakis, N. A. (2011). Social network concordance in food choice among spouses, friends, and siblings. American Journal of Public Health, 101(11), 2170-2177.

Pornpitakpan, C. (2004). The persuasiveness of source credibility: A critical review of five decades' evidence. Journal of Applied Social Psychology, 34(2), 243-281.

Prochaska, J. O., Norcross, J. C., \& DiClemente, C. C. (2013). Applying the stages of change. Psychotherapy in Australia, 19(2), 10-15.

R Core Team. (2017). R: A language and environment for statistical computing. R Foundation for Statistical Computing [Computer Software]. Vienna, Austria: The R Foundation.

Richetin, J., Conner, M., \& Perugini, M. (2011). Not doing is not the opposite of doing: 
Implications for attitudinal models of behavioral prediction. Personality and Social Psychology Bulletin, 37(1), 40-54.

Rivis, A., \& Sheeran, P. (2003). Descriptive norms as an additional predictor in the theory of planned behaviour: A meta-analysis. Current Psychology, 22(3), 218-233.

Rosseel, Y. (2012). lavaan: An R package for structural equation modeling. Journal of Statistical Software, 48(2), 1-36.

Saint-Maurice, P. F., Kim, Y., Hibbing, P., Oh, A. Y., Perna, F. M., \& Welk, G. J. (2017). Calibration and validation of the Youth Activity Profile: The FLASHE study. American Journal of Preventive Medicine, 52(6), 880-887.

Saint-Maurice, P. F., \& Welk, G. J. (2015). Validity and calibration of the Youth Activity Profile. PloS One, 10(12), e0143949.

Sheeran, P., Klein, W. M., \& Rothman, A. J. (2017). Health behavior change: Moving from observation to intervention. Annual Review of Psychology, 68, 573-600.

Sheeran, P., Maki, A., Montanaro, E., Avishai-Yitshak, A., Bryan, A., Klein, W. M., ... Rothman, A. J. (2016). The impact of changing attitudes, norms, and self-efficacy on health-related intentions and behavior: A meta-analysis. Health Psychology, 35(11), 11781188.

Simpson, J. A., Farrell, A. K., Oriña, M. M., \& Rothman, A. J. (2015). Power and social influence in relationships. In M. Mikulincer, P. R. Shaver, J. A. Simpson, \& J. F. Dovidio (Eds.), APA handbook of personality and social psychology, Vol. 3. Interpersonal relations (pp. 393-420). Washington, DC: APA.

Smith, T. M., Calloway, E. E., Pinard, C. A., Hennessy, E., Oh, A. Y., Nebeling, L. C., \& Yaroch, A. L. (2017). Using secondary 24-hour dietary recall data to estimate daily dietary 
factor intake from the FLASHE study dietary screener. American Journal of Preventive Medicine, 52(6), 856-862.

Sparks, P., \& Guthrie, C. A. (1998). Self-identity and the theory of planned behavior: A useful addition or an unhelpful artifice? Journal of Applied Social Psychology, 28(15), 13931410.

Taverno Ross, S. E., Larson, N., Graham, D. J., \& Neumark-Sztainer, D. (2014). Longitudinal changes in physical activity and sedentary behavior from adolescence to adulthood: Comparing U.S.-born and foreign-born populations. Journal of Physical Activity and Health, 11(3), 519-527.

The IPAQ Group (2016). IPAQ scoring protocol [Questionnaire Resource]. Retrieved from: https://sites.google.com/site/theipaq/scoring-protocol.

Thompson, F. E., Midthune, D., Kahle, L., \& Dodd, K. W. (2017). Development and evaluation of the National Cancer Institute's dietary screener questionnaire scoring algorithms -3 . The Journal of Nutrition, 147(6), 1226-1233.

Uchino, B. N. (2006). Social support and health: A review of physiological processes potentially underlying links to disease outcomes. Journal of Behavioral Medicine, 29(4), 377-387.

Wang, Y., Beydoun, M. A., Li, J., Liu, Y., \& Moreno, L. A. (2011). Do children and their parents eat a similar diet? Resemblance in child and parental dietary intake: Systematic review and meta-analysis. Journal of Epidemiology \& Community Health, 65(2), 177-189.

Weinstein, N. D. (2007). Misleading tests of health behavior theories. Annals of Behavioral Medicine, 33(1), 1-10.

Wilson, G., \& Wood, K. (2004). The influence of children on parental purchases during supermarket shopping. International Journal of Consumer Studies, 28(4), 329-336. 
Table 1.

Model I and Model II: APIM Fit Statistics and $R^{2}$

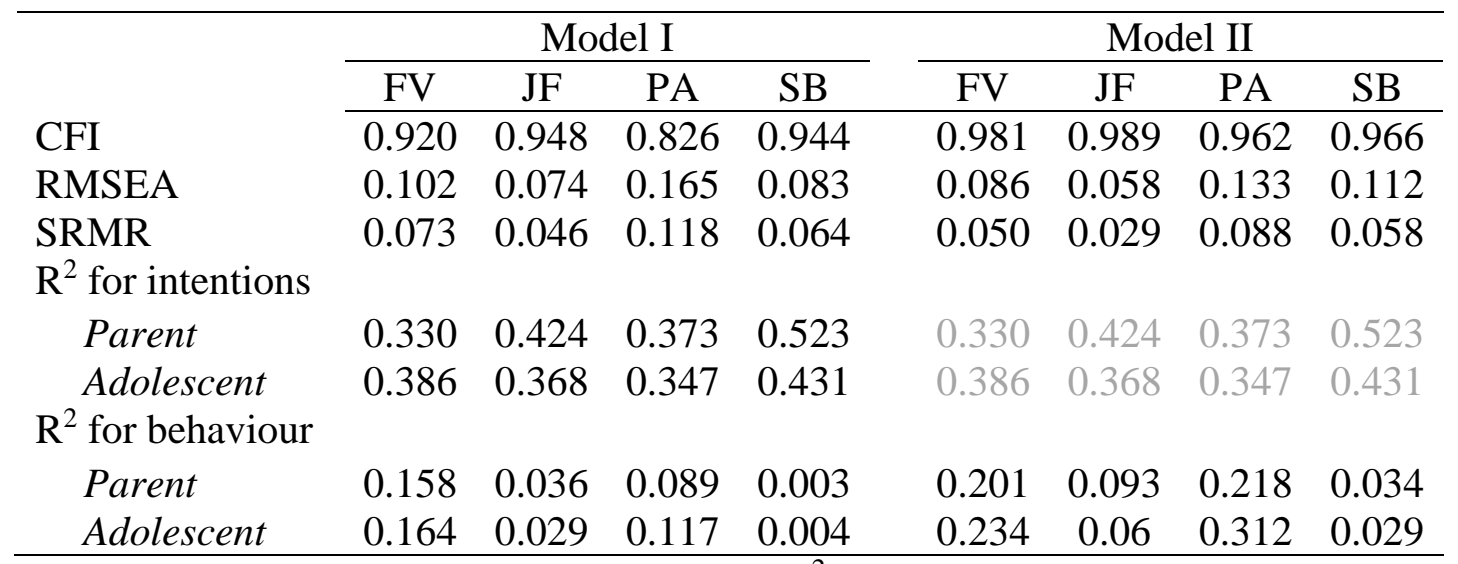

Note. Model II's coefficients of determination $\left(\mathrm{R}^{2}\right)$ for intentions (lighter grey) are equivalent to those for Model I. APIM = Actor-Partner Interdependence Model; FV = Fruit and vegetable consumption; JF = Junk food and sugary drinks consumption; PA = Physical activity; $\mathrm{SB}=$ Screen time sedentary behaviour; $\mathrm{PBC}=$ Perceived behavioural control. Ideal model fit was defined as a CFI close to or higher than .95, a RMSEA close to or less than .06, and a SRMR close to or lower than .08 (Hu \& Bentler, 1999). Most models had good fits, approaching or surpassing the CFI and SRMR thresholds most of the time, but RMSEA tended to be higher than .06. RMSEA values were not interpreted as problematic, given that this index can be a poor indicator of fit for complex models (Iacobucci, 2010). 
Table 2.

Standardized Intrapersonal (Actor) Effect Estimates from APIM Models in Figure 1

\begin{tabular}{|c|c|c|c|c|c|c|c|c|c|c|c|}
\hline \multirow{2}{*}{ Actor } & \multirow{2}{*}{ Outcome } & \multirow{2}{*}{$\sim$} & \multirow{2}{*}{ Predictor } & \multicolumn{4}{|c|}{ Model I } & \multicolumn{4}{|c|}{ Model II ${ }^{\mathrm{a}}$} \\
\hline & & & & $\mathrm{FV}$ & $\mathrm{JF}$ & PA & SB & $\mathrm{FV}$ & $\mathrm{JF}$ & $\mathrm{PA}$ & SB \\
\hline \multicolumn{12}{|l|}{ Parent } \\
\hline & Intention & $\sim$ & Attitudes & $0.471 * * *$ & $0.587 * * *$ & $0.486 * * *$ & $0.601 * * *$ & $0.472 * * *$ & $0.587 * * *$ & $0.487 * * *$ & $0.601 * * *$ \\
\hline & & $\sim$ & Norms & $0.082 * * *$ & $0.079 * * *$ & $0.125 * * *$ & $0.184 * * *$ & $0.082 * *$ & $0.079 * * *$ & $0.125 * * *$ & $0.184 * * *$ \\
\hline & & $\sim$ & $\mathrm{PBC}$ & $0.188 * * *$ & $0.150 * * *$ & $0.166 * * *$ & $0.113 * * *$ & $0.189 * * *$ & $0.149 * * *$ & $0.165 * * *$ & $0.112 * * *$ \\
\hline & Behaviour & $\sim$ & Intentions & $0.325 * * *$ & $0.183 * * *$ & $0.268 * * *$ & 0.041 & $0.218 * * *$ & $0.119 * * *$ & 0.018 & $0.065^{t}$ \\
\hline & & $\sim$ & Attitudes & - & - & - & - & $0.054 *$ & $0.064 *$ & $0.050 *$ & 0.000 \\
\hline & & $\sim$ & Norms & - & - & - & - & $0.042^{t}$ & $-0.16 * * *$ & $0.208 * * *$ & $-0.116 * * *$ \\
\hline & & $\sim$ & $\mathrm{PBC}$ & - & - & - & - & $0.198 * * *$ & $0.156^{* * * *}$ & 0.032 & $0.12 * * *$ \\
\hline \multicolumn{12}{|l|}{ Adolescent } \\
\hline & Intention & $\sim$ & Attitudes & $0.377 * * *$ & $0.463 * * *$ & $0.446 * * *$ & $0.482 * * *$ & 0.377 *** & $0.463 * * *$ & $0.446 * * *$ & $0.482 * * *$ \\
\hline & & $\sim$ & Norms & $0.066^{* *}$ & $0.049 *$ & $0.094 * * *$ & $0.171 * * *$ & $0.066 * *$ & $0.049 *$ & $0.094 * * *$ & $0.171 * * *$ \\
\hline & & $\sim$ & $\mathrm{PBC}$ & $0.320 * * *$ & $0.259 * * *$ & $0.124 * * *$ & $0.200 * * *$ & $0.320 * * *$ & $0.259 * * *$ & $0.124 * * *$ & $0.199 * * *$ \\
\hline & Behaviour & $\sim$ & Intentions & $0.367 * * *$ & $0.159 * * *$ & $0.333 * * *$ & $0.061 *$ & $0.197 * * *$ & $0.105 * * *$ & 0.022 & -0.011 \\
\hline & & $\sim$ & Attitudes & - & - & - & - & 0.009 & 0.019 & $0.301 * * *$ & -0.002 \\
\hline & & $\sim$ & Norms & - & - & - & - & $0.114 * * *$ & $0.102 * * *$ & $0.131 * * *$ & $0.115 * * *$ \\
\hline & & $\sim$ & $\mathrm{PBC}$ & - & - & - & - & $0.245^{* * *}$ & $0.098 * * *$ & $0.244 * * *$ & $0.106 * * *$ \\
\hline
\end{tabular}

Note. APIM = Actor-Partner Interdependence Model; FV = Fruit and vegetable consumption; JF = Junk food and sugary drinks

consumption; PA = Physical activity; SB = Screen time sedentary behaviour; $\mathrm{PBC}=$ Perceived behavioural control.

aBecause the modelling of intentions is identical across Models I and II, estimates for Model II are presented in lighter grey font.

$* * * p<.001 * * p<.01 * p<.05 \quad{ }^{\mathrm{t}} p<.10$ 
Table 3.

Standardized Interpersonal (Partner) Effect Estimates from APIM Models in Figure 1

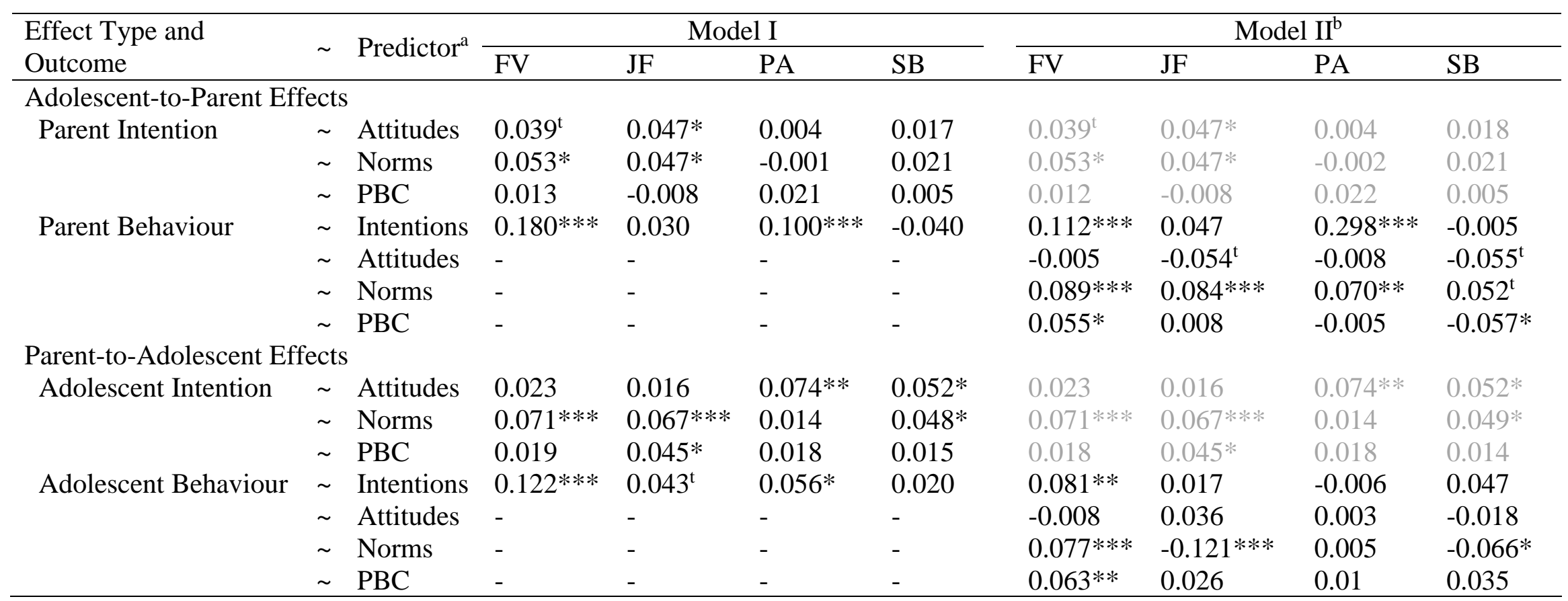

Note. APIM = Actor-Partner Interdependence Model; FV = Fruit and vegetable consumption; JF = Junk food and sugary drinks

consumption; PA = Physical activity; SB = Screen time sedentary behaviour; PBC = Perceived behavioural control.

apredictors are characteristics of the partner (i.e., parent outcomes are predicted by adolescent characteristics; adolescent outcomes are predicted by parent characteristics).

${ }^{b}$ Because the modelling of intentions is identical across Models I and II, estimates for Model II are presented in lighter grey font.

$* * * p<.001 * * p<.01 * p<.05 \quad \mathrm{t} p<.10$ 
Table 4.

Summary of Interpersonal (Partner) Effect Patterns Across Behaviours

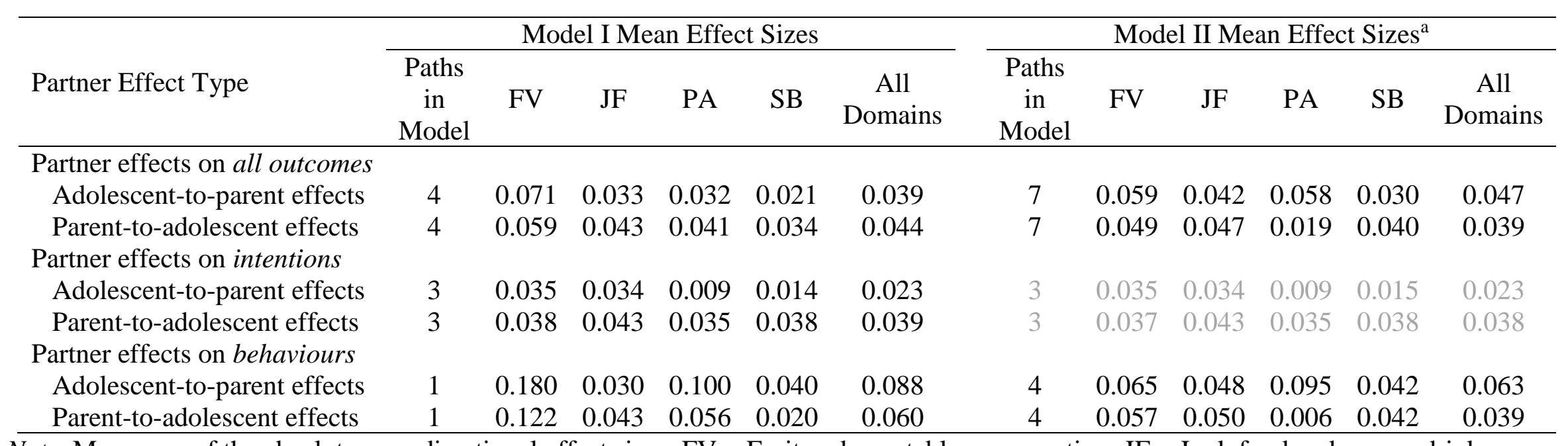

Note. Means are of the absolute, non-directional effect sizes. FV = Fruit and vegetable consumption; JF = Junk food and sugary drinks

consumption; $\mathrm{PA}=$ Physical activity; $\mathrm{SB}=$ Screen time sedentary behaviour.

a Because the modelling of intentions is identical across Models I and II, estimates for Model II are presented in lighter grey font. 

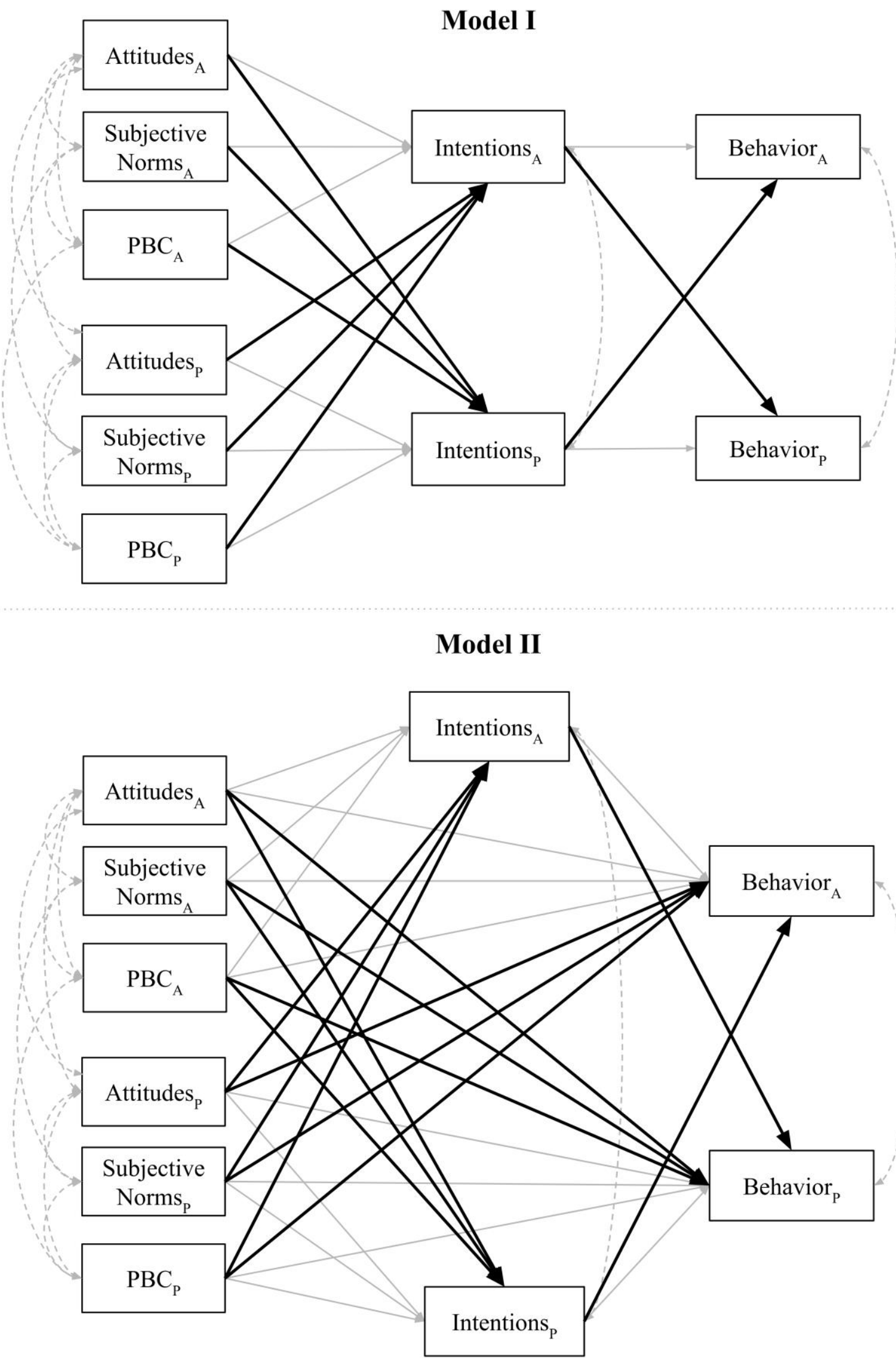

Figure 1. 


\section{Figure Captions}

Figure 1. Subscripts denote Adolescent $(\mathrm{A})$ and Parent $(\mathrm{P})$ variables. $\mathrm{PBC}=$ Perceived behavioural control. Bold unidirectional paths represent interpersonal (partner) effects. Grey unidirectional paths represent intrapersonal (actor) effects. Grey dashed paths represent correlations that account for interdependence between dyad members (i.e., correlations between all equivalent variables between persons), and similarity in item responses within person (e.g., correlations between adolescent attitudes, subjective norms, and PBC). Correlations between different belief types across persons are not included (e.g., between adolescent attitudes and parent $\mathrm{PBC})$. 


\section{Supplemental Files}

Table S1.

Descriptive Statistics for Parents and Adolescents in FLASHE Dyads $(N$ dyads $=1,717)$

\begin{tabular}{lc|lc}
\hline Characteristic & $\mathrm{n}(\%)$ & Characteristic & $\mathrm{n}(\%)$ \\
\hline $\begin{array}{c}\text { Parent Sex } \\
\text { Male }\end{array}$ & $443(26 \%)$ & $\begin{array}{l}\text { Dyad Type } \\
\text { Mother - Daughter }\end{array}$ \\
Female & $1259(74 \%)$ & $\begin{array}{l}\text { Mother - Son } \\
\text { Father - Daughter }\end{array}$ & $599(36 \%)$ \\
Adolescent Sex & & Father - Son & $632(38 \%)$ \\
Male & $827(50 \%)$ & $199(12 \%)$ \\
Female & $836(50 \%)$ & Parent Education & $226(14 \%)$ \\
Parent Age & & Less than a 4-year college degree & $905(53 \%)$ \\
$18-34$ & $191(11 \%)$ & 4-year college degree or higher & $792(47 \%)$ \\
$35-44$ & $743(44 \%)$ & Parent Race/Ethnicity & $1176(70 \%)$ \\
$45-59$ & $718(42 \%)$ & Non-Hispanic White Only & $290(17 \%)$ \\
$>=60$ & $50(3 \%)$ & Non-Hispanic Black Only & $122(7 \%)$ \\
Adolescent Age & & Hispanic & $99(6 \%)$ \\
12 & $222(13 \%)$ & Other & $1053(64 \%)$ \\
13 & $333(20 \%)$ & Adolescent Race/Ethnicity & $279(17 \%)$ \\
14 & $279(17 \%)$ & Non-Hispanic White Only & $166(10 \%)$ \\
15 & $301(18 \%)$ & Non-Hispanic Black Only & $153(9 \%)$ \\
16 & $328(20 \%)$ & Hispanic & \\
17 & $204(12 \%)$ & Other &
\end{tabular}


Table S2.

Means and Standard Deviations for Each Behaviour Outcome

\begin{tabular}{llcccc}
\hline & & \multicolumn{4}{c}{ Behavioural Domain } \\
\cline { 3 - 6 } $\begin{array}{l}\text { Dyad } \\
\text { Member }\end{array}$ & Construct & FV & JF & PA $^{\mathrm{a}}$ & SB $^{\mathrm{a}}$ \\
\hline Parent & Attitudes & $4.50(0.70)$ & $1.56(0.78)$ & $3.88(0.81)$ & $2.66(1.19)$ \\
& Norms $^{\mathrm{a}}$ & $2.13(1.19)$ & $3.66(1.27)$ & $2.17(1.17)$ & $3.64(1.23)$ \\
& PBC & $4.02(1.19)$ & $2.11(1.15)$ & $3.52(1.34)$ & $2.12(1.10)$ \\
& Intentions & $4.13(0.92)$ & $1.84(0.95)$ & $3.98(1.00)$ & $2.97(1.24)$ \\
& Behaviour & $2.37(0.69)$ & $1.68(0.46)$ & $3565(3782)$ & $1.46(0.63)$ \\
Adolescent & Attitudes & $4.22(0.89)$ & $1.92(0.96)$ & $3.96(0.82)$ & $2.80(1.17)$ \\
& Norms $^{\mathrm{a}}$ & $3.17(0.88)$ & $3.49(0.80)$ & $3.00(0.94)$ & $3.58(0.79)$ \\
& PBC & $4.03(1.09)$ & $2.42(1.17)$ & $3.86(1.13)$ & $2.51(1.15)$ \\
& Intentions & $3.65(1.12)$ & $2.40(1.14)$ & $3.78(1.04)$ & $3.31(1.22)$ \\
& Behaviour & $2.26(0.75)$ & $1.92(0.53)$ & $0.45(0.22)$ & $1.81(0.76)$ \\
\hline
\end{tabular}

Note. Due to missing data, sample size per item ranged from 1478 to 1646 . FV = Fruit and

vegetable consumption; $\mathrm{JF}=\mathrm{Junk}$ food and sugary drinks consumption; PA = Physical activity;

$\mathrm{SB}=$ Screen time sedentary behaviour; $\mathrm{PBC}=$ Perceived behavioural control.

${ }^{a}$ Different instruments were used to assess parent and adolescent behaviours in the PA and SB

domains. Measures of subjective norms for adolescents contained one additional item, compared

to our measure of parent subjective norms. All other measures used identical items for parents

and adolescents. 
Table S3.

Correlation Table for Parent/Adolescent Variables in the Fruit and Vegetable Consumption (FV) Domain

\begin{tabular}{|c|c|c|c|c|c|c|c|c|c|c|}
\hline & 1 & 2 & 3 & 4 & 5 & 6 & 7 & 8 & 9 & 10 \\
\hline 1. Parent Attitudes & - & 0.026 & $0.265^{* * *}$ & $0.544 * * *$ & $0.265 * * *$ & $0.291 * * *$ & $0.149 * * *$ & $0.107 * * *$ & $0.183 * * *$ & $0.137 * * *$ \\
\hline 2. Parent Norms & & - & 0.033 & $0.122 * * *$ & $0.124 * * *$ & $0.077 * *$ & $0.331 * * *$ & $0.055^{*}$ & $0.140 * * *$ & $0.168 * * *$ \\
\hline 3. Parent PBC & & & 一 & $0.331 * * *$ & $0.327 * * *$ & $0.088 * * *$ & $0.143^{* * *}$ & $0.211 * * *$ & $0.138 * * *$ & $0.187 * * *$ \\
\hline 4. Parent Intentions & & & & - & $0.370 * * *$ & $0.219 * * *$ & $0.192 * * *$ & $0.136 * * *$ & $0.247 * * *$ & $0.214 * * *$ \\
\hline 5. Parent FV Behaviour & & & & & - & $0.191 * * *$ & $0.226^{* * *}$ & $0.212 * * *$ & $0.260 * * *$ & $0.531 * * *$ \\
\hline 6. Adolescent Attitudes & & & & & & - & $0.299 * * *$ & $0.425 * * *$ & $0.547 * * *$ & $0.281 * * *$ \\
\hline 7. Adolescent Norms & & & & & & & 一 & $0.254 * * *$ & $0.290 * * *$ & $0.285 * * *$ \\
\hline 8. Adolescent PBC & & & & & & & & - & $0.507 * * *$ & $0.405 * * *$ \\
\hline 9. Adolescent Intentions & & & & & & & & & - & $0.397 * * *$ \\
\hline 10. Adolescent FV & & & & & & & & & & \\
\hline Behaviour & & & & & & & & & & \\
\hline
\end{tabular}

Note. $\mathrm{FV}=$ Fruit and vegetable consumption

$* * * \mathrm{p}<.001 * * \mathrm{p}<.01 * \mathrm{p}<.05$ 
Table S4.

Correlation Table for Parent/Adolescent Variables in the Junk Food and Sugary Drinks Consumption (JF) Domain

\begin{tabular}{|c|c|c|c|c|c|c|c|c|c|c|}
\hline & 1 & 2 & 3 & 4 & 5 & 6 & 7 & 8 & 9 & 10 \\
\hline 1. Parent Attitudes & - & $0.067 * *$ & $0.174 * * *$ & $0.632 * * *$ & $0.158 * * *$ & $0.247 * * *$ & $0.079 * *$ & $0.062 *$ & $0.162 * * *$ & $0.078 * *$ \\
\hline 2. Parent Norms & & - & $-0.066^{* *}$ & $0.120 * * *$ & $-0.131 * * *$ & $0.069 * *$ & $0.223 * * *$ & $0.056^{*}$ & $0.122 * * *$ & $-0.076^{* *}$ \\
\hline 3. Parent PBC & & & - & $0.250 * * *$ & $0.215 * * *$ & $0.088 * * *$ & $0.049 *$ & $0.175^{* * *}$ & $0.133 * * *$ & $0.082 * * *$ \\
\hline 4. Parent Intentions & & & & - & $0.188 * * *$ & $0.216^{* * *}$ & $0.122 * * *$ & $0.075 * *$ & $0.233 * * *$ & $0.080 * *$ \\
\hline 5. Parent JF Behaviour & & & & & - & 0.031 & $0.074 * *$ & 0.047 & $0.072 * *$ & $0.582 * * *$ \\
\hline 6. Adolescent Attitudes & & & & & & - & $0.156 * * *$ & $0.268 * * *$ & $0.552 * * *$ & $0.126 * * *$ \\
\hline 7. Adolescent Norms & & & & & & & - & $0.049 *$ & $0.152 * * *$ & $0.105 * * *$ \\
\hline 8. Adolescent PBC & & & & & & & & - & $0.398 * * *$ & $0.151 * * *$ \\
\hline 9. Adolescent Intentions & & & & & & & & & - & $0.169 * * *$ \\
\hline 10. Adolescent JF & & & & & & & & & & \\
\hline Behaviour & & & & & & & & & & \\
\hline
\end{tabular}

Note. $\mathrm{JF}=$ Junk food and sugary drinks consumption

$* * * \mathrm{p}<.001 * * \mathrm{p}<.01 * \mathrm{p}<.05$ 
Table S5.

Correlation Table for Parent/Adolescent Variables in the Physical Activity (PA) Domain

\begin{tabular}{|c|c|c|c|c|c|c|c|c|c|c|}
\hline & 1 & 2 & 3 & 4 & 5 & 6 & 7 & 8 & 9 & 10 \\
\hline 1. Parent Attitudes & - & $0.090 * * *$ & $0.513 * * *$ & $0.589 * * *$ & $0.413 * * *$ & $0.327 * * *$ & $0.202 * * *$ & $0.272 * * *$ & $0.282 * * *$ & $0.215^{* * *}$ \\
\hline 2. Parent Norms & & - & $0.073 * *$ & $0.182 * * *$ & $0.113 * * *$ & $0.092 * * *$ & $0.315^{* * *}$ & $0.068 * *$ & $0.101 * * *$ & $0.092 * * *$ \\
\hline 3. Parent PBC & & & - & $0.427 * * *$ & $0.362 * * *$ & $0.190 * * *$ & $0.119 * * *$ & $0.180 * * *$ & $0.174 * * *$ & $0.133 * * *$ \\
\hline 4. Parent Intentions & & & & - & $0.281 * * *$ & $0.219 * * *$ & $0.165^{* * *}$ & $0.195 * * *$ & $0.273 * * *$ & $0.147 * * *$ \\
\hline 5. Parent PA Behaviour & & & & & - & $0.163 * * *$ & $0.169 * * *$ & $0.146 * * *$ & $0.165 * * *$ & $0.262 * * *$ \\
\hline 6. Adolescent Attitudes & & & & & & - & $0.330 * * *$ & $0.656 * * *$ & $0.588 * * *$ & $0.517 * * *$ \\
\hline 7. Adolescent Norms & & & & & & & - & $0.313 * * *$ & $0.302 * * *$ & $0.315^{* * *}$ \\
\hline 8. Adolescent PBC & & & & & & & & - & $0.471 * * *$ & $0.494 * * *$ \\
\hline 9. Adolescent Intentions & & & & & & & & & - & $0.349 * * *$ \\
\hline 10. Adolescent PA & & & & & & & & & & \\
\hline Behaviour & & & & & & & & & & \\
\hline
\end{tabular}

Note. $\mathrm{PA}=$ Physical Activity

$* * * \mathrm{p}<.001 * * \mathrm{p}<.01 * \mathrm{p}<.05$ 
Table S6.

Correlation Table for Parent/Adolescent Variables in the Screen Time Sedentary Behaviour (SB) Domain

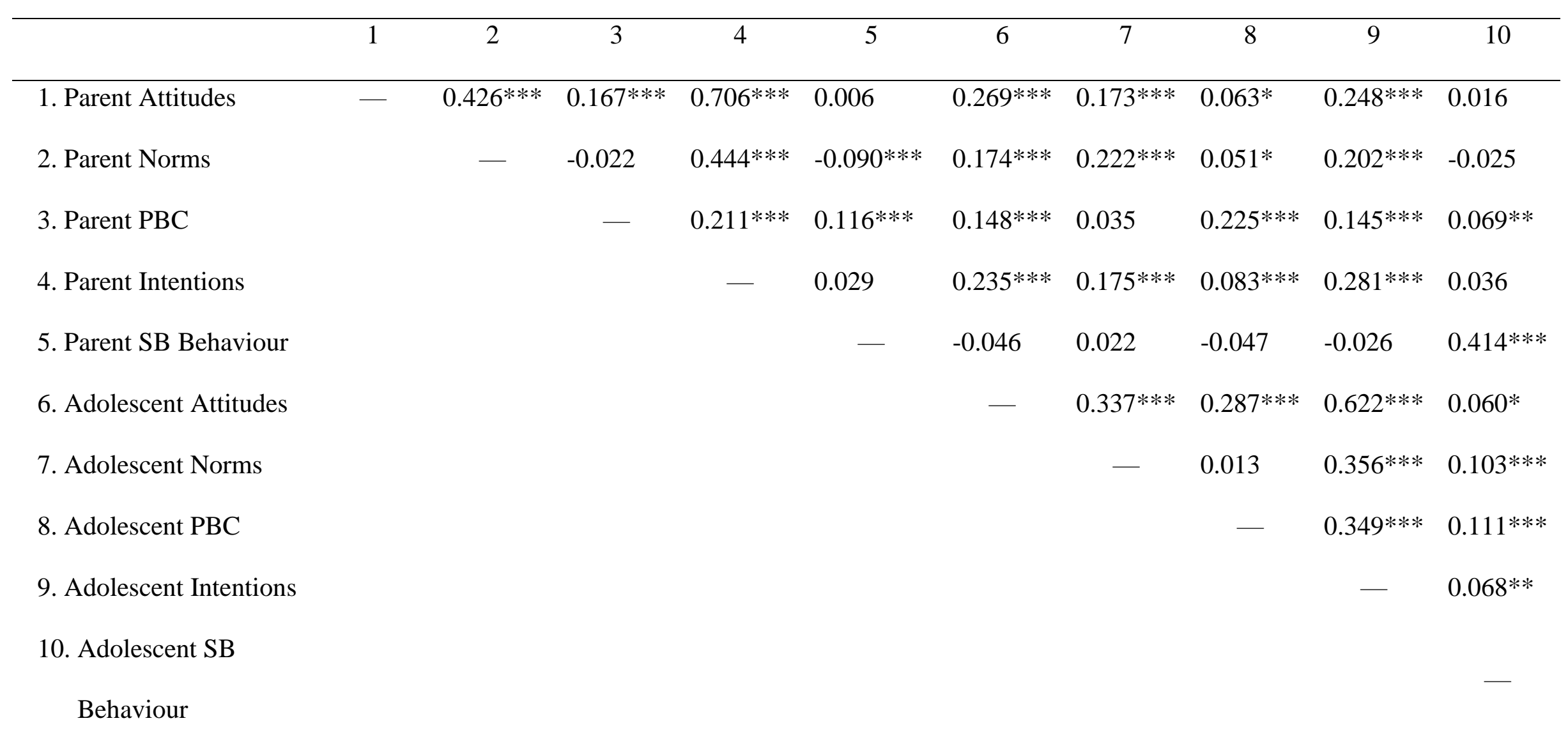

Note. $\mathrm{SB}=$ Screen Time Sedentary Behaviour

$* * * \mathrm{p}<.001 * * \mathrm{p}<.01 * \mathrm{p}<.05$ 


\section{Alternate Model, changing the direction of the intentions-behaviour link.}

Given that the sample was cross-sectional, our assessment of health behaviours was dependent on the degree to which participants had previously engaged in a given health behaviour. Consequently, the direction of the effect between intentions and behaviours could not be established, and one could reasonably model behaviour as a predictor of intentions, rather than the reverse. The results of doing this, would lead to the model represented below (Figure S1). The results that emerge from an analysis of this model are presented in Tables S7 to S9.

Overall, the conclusions drawn from this Alternate Model are very much in line with the findings drawn from our Models 1 and 2:

- The intrapersonal effects of attitudes, subjective norms, and PBC on intentions are significant across all four behavioural domains. The intrapersonal effects of behaviour on people's own intentions are significant for only half the pathways. These intrapersonal effects mirror the corresponding intrapersonal effects in Model 2 (Table 2). This is not surprising given that the Alternate Model: (1) still posits the same within-person associations, but simply reverses the directions of the intentions-behaviour link, and (2) operationalizes the TPB beliefs-to-behaviour links (from Model 2) as correlations instead. Therefore, modelling behaviours as an antecedent, correlate, or outcome of intentions does not change our overall interpretation-these 2 variables are still significantly associated.

- Regarding the interpersonal effects, the Alternate Model differs from both Models 1 and 2 in more ways than simply reversing the direction of the intentions-behaviour link. Specifically, it differs from Model 1 in modelling correlations between each person's own TPB beliefs and their own behaviours (whereas Model 1 did not model any 
equivalent paths; Model 2, however, included comparable paths). The Alternate Model also differs from Model 2 by not modelling any association between each person's TPB beliefs and the other person's behaviour. Despite these differences, we still draw the same general observations with the Alternate Model as with our original analyses (Models 1 and 2): First, interpersonal effects still emerge in each behavioural domain. Second, the interpersonal effects of parent characteristics on adolescent intentions remain more prominent than the interpersonal effects of adolescent variables on parent intentions. Third, the relative frequency with which each TPB belief has significant associations with the other person's intentions remain. Subjective norms have the most frequent (and largest average) associations, followed by attitudes, and then PBC.

- Adding behaviour as a predictor of intentions in the Alternate Model does not explain much additional variance in intentions beyond the three TPB belief variables. The average coefficient of determination (R2) for predicting intentions in Models 1 and 2 was .398. Adding behaviour as a predictor of intentions increases the R2 by only .006. This lack of additional variance explained may suggest that this addition may not be meaningful or warranted.

Although these findings are largely in line with what we would expect (and converge with our findings from Models 1 and 2), we note that the Alternative model in Figure S1 was not preregistered. Consequently, the findings reported here should be considered post hoc analyses. 


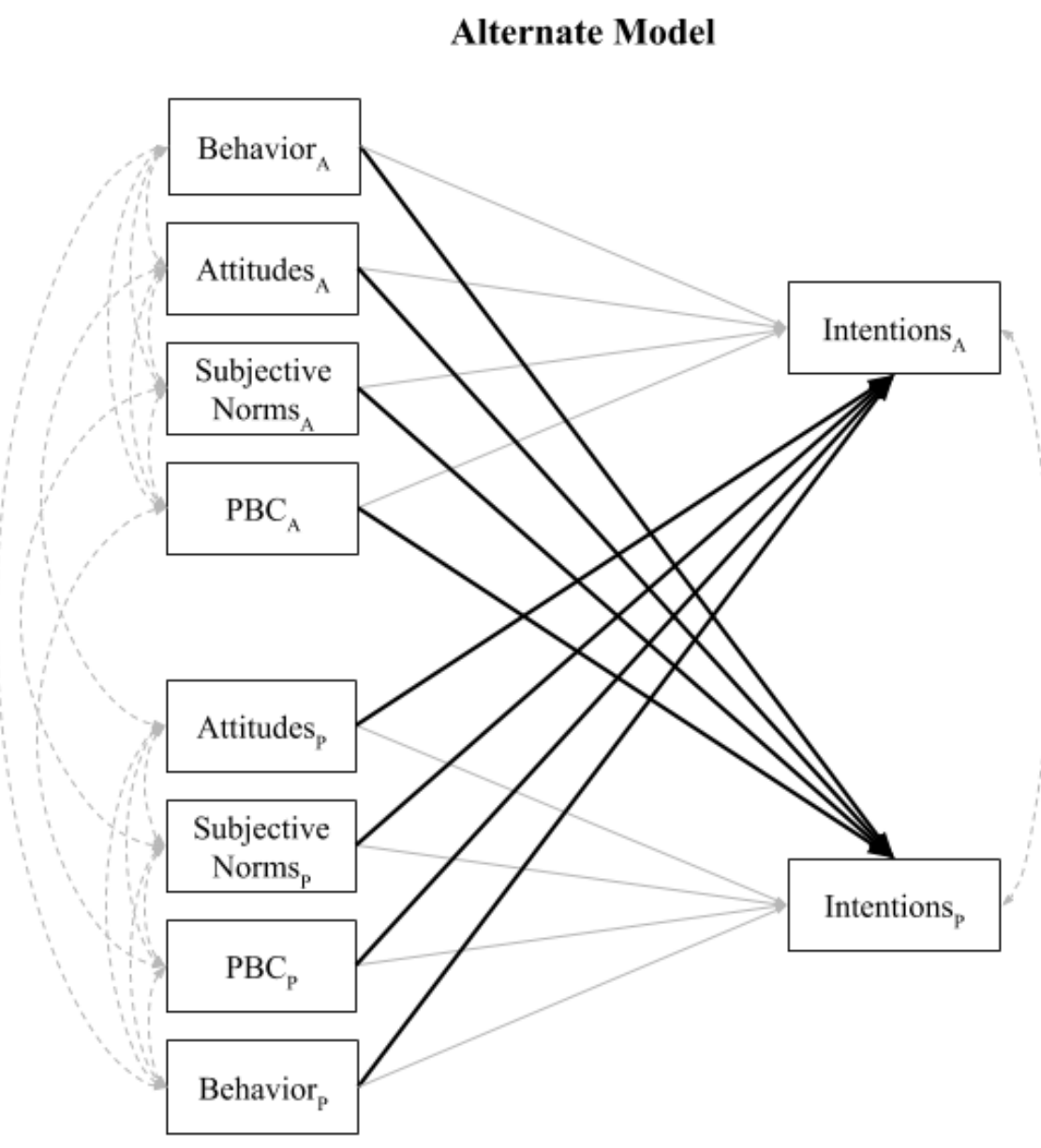

Figure S1. Alternate Model. Subscripts denote Adolescent $(\mathrm{A})$ and Parent $(\mathrm{P})$ variables. $\mathrm{PBC}=$ Perceived behavioural control. Bold unidirectional paths represent interpersonal (partner) effects. Grey unidirectional paths represent intrapersonal (actor) effects. Grey dashed paths represent correlations that account for interdependence between dyad members (i.e., correlations between all equivalent variables between persons), and similarity in item responses within person (e.g., correlations between adolescent attitudes, subjective norms, and $\mathrm{PBC}$ ). Correlations between different belief types across persons are not estimated (e.g., between adolescent attitudes and parent $\mathrm{PBC})$. 
Table S7.

Model Fit Statistics and $R^{2}$ for alternate model predicting intentions

\begin{tabular}{lcccc}
\hline & \multicolumn{4}{c}{ Alternate Model } \\
\cline { 2 - 5 } & FV & JF & PA & SB \\
\cline { 2 - 5 } CFI & 0.939 & 0.980 & 0.958 & 0.963 \\
RMSEA & 0.109 & 0.057 & 0.100 & 0.083 \\
SRMR & 0.089 & 0.039 & 0.098 & 0.059 \\
$\mathrm{R}^{2}$ for intentions & & & & \\
$\quad$ Parent & 0.353 & 0.430 & 0.374 & 0.524 \\
$\quad$ Adolescent & 0.396 & 0.372 & 0.347 & 0.431 \\
\hline
\end{tabular}

Note. $\mathrm{FV}=$ Fruit and vegetable consumption; JF = Junk food and sugary drinks consumption; PA

$=$ Physical activity; $\mathrm{SB}=$ Screen time sedentary Behaviour; $\mathrm{PBC}=$ Perceived behavioural control. 
Table S8.

Standardized Intrapersonal (Actor) Effect Estimates from APIM Alternate Model in Figure S1.

\begin{tabular}{|c|c|c|c|c|c|c|}
\hline \multirow{2}{*}{$\begin{array}{l}\text { Actor and } \\
\text { Outcome }\end{array}$} & \multirow{2}{*}{$\sim$} & \multirow{2}{*}{ Predictor } & \multicolumn{4}{|c|}{ Alternate Model } \\
\hline & & & $\mathrm{FV}$ & $\mathrm{JF}$ & PA & SB \\
\hline \multicolumn{7}{|c|}{ Parent Intentions } \\
\hline & $\sim$ & Attitudes & $0.442 * * *$ & $0.575 * * *$ & $0.481 * * *$ & $0.600 * * *$ \\
\hline & $\sim$ & Norms & $0.070 * * *$ & $0.089 * * *$ & $0.124 * * *$ & $0.187 * * *$ \\
\hline & $\sim$ & $\mathrm{PBC}$ & $0.144 * * *$ & $0.133 * * *$ & $0.162 * * *$ & $0.109 * * *$ \\
\hline & $\sim$ & Behaviour & $0.184 * * *$ & $0.100 * * *$ & 0.018 & 0.026 \\
\hline \multicolumn{7}{|c|}{ Adolescent Intentions } \\
\hline & $\sim$ & Attitudes & $0.363 * * *$ & $0.458 * * *$ & $0.445 * * *$ & $0.483 * * *$ \\
\hline & $\sim$ & Norms & $0.043 *$ & $0.041 *$ & $0.092 * * *$ & $0.172 * * *$ \\
\hline & $\sim$ & $\mathrm{PBC}$ & $0.272 * * *$ & $0.250 * * *$ & $0.123 * * *$ & $0.200 * * *$ \\
\hline & $\sim$ & Behaviour & $0.141 * * *$ & $0.069 * *$ & 0.003 & -0.004 \\
\hline
\end{tabular}

Note. $\mathrm{FV}=$ Fruit and vegetable consumption; $\mathrm{JF}=$ Junk food and sugary drinks consumption; PA

$=$ Physical activity SB $=$ Screen time sedentary behaviour; $\mathrm{PBC}=$ Perceived behavioural control.

$* * * p<.001 * * p<.01 * p<.05 \quad \mathrm{t} p<.1$ 
Table S9.

Standardized Interpersonal (Partner) Effect Estimates from APIM Alternate Model in Figure S1.

\begin{tabular}{|c|c|c|c|c|c|c|}
\hline \multirow[t]{2}{*}{ Effect Type and Outcome } & \multirow{2}{*}{$\sim$} & \multirow{2}{*}{ Predictor $^{\mathrm{a}}$} & \multicolumn{4}{|c|}{ Alternate Model } \\
\hline & & & $\mathrm{FV}$ & JF & PA & SB \\
\hline \multicolumn{7}{|l|}{ Adolescent-to-Parent Effects } \\
\hline \multirow[t]{4}{*}{ Parent Intention } & $\sim$ & Attitudes & 0.031 & $0.052 * *$ & 0.006 & 0.019 \\
\hline & $\sim$ & Norms & 0.033 & $0.042 *$ & -0.002 & 0.018 \\
\hline & $\sim$ & PBC & -0.005 & -0.006 & 0.024 & 0.005 \\
\hline & $\sim$ & Behaviour & 0.001 & -0.038 & -0.008 & 0.011 \\
\hline \multicolumn{7}{|l|}{ Parent-to-Adolescent Effects } \\
\hline \multirow[t]{4}{*}{ Adolescent Intention } & $\sim$ & Attitudes & 0.012 & 0.012 & $0.066 * *$ & $0.052 *$ \\
\hline & $\sim$ & Norms & $0.055 * *$ & $0.075 * * *$ & 0.013 & $0.049 *$ \\
\hline & $\sim$ & $\mathrm{PBC}$ & 0.002 & $0.042 *$ & 0.013 & 0.014 \\
\hline & $\sim$ & Behaviour & $0.039^{t}$ & 0.001 & 0.025 & 0.003 \\
\hline
\end{tabular}

Note. $\mathrm{FV}=$ Fruit and vegetable consumption; JF = Junk food and sugary drinks consumption; PA

$=$ Physical activity $; \mathrm{SB}=$ Screen time sedentary behaviour; $\mathrm{PBC}=$ Perceived behavioural control.

aredictors are characteristics of the partner (i.e., parent outcomes are predicted by adolescent characteristics; adolescent outcomes are predicted by parent characteristics).

$* * * p<.001 * * p<.01 * p<.05 \quad{ }^{\mathrm{t}} p<.1$ 